\title{
Efeito dos agentes de compatibilização SBS e SEBS-MA no desempenho de misturas de poliestireno/resíduo de borracha de SBR
}

\author{
Effect of SBS and SEBS-MA compatibilizing \\ agents on the performance of Polystyrene/ \\ Rubber residue (SBR) mixtures
}

Carlos Bruno Barreto Luna ${ }^{1}$, Divânia Ferreira da Silva ${ }^{1}$, Edcleide Maria Araújo ${ }^{1}$, Tomás Jeferson Alves de Melo ${ }^{1}$, Amanda Dantas de Oliveira ${ }^{2}$

\footnotetext{
${ }^{1}$ Unidade Acadêmica de Engenharia de Materiais, UAEMa/CCT/UFCG, Rua: Aprígio Veloso, 882, cep 58429-140, Campina Grande, PB.

${ }^{2}$ Departamento de Engenharia de Materiais, Centro de Desenvolvimento Tecnológico/UFPel, Rua: Félix da Cunha, 809, CEP 96010-000, Pelotas, RS e-mail: brunobarretodemaufcg@hotmail.com; divaniaf@yahoo.com.br; edcleide.araujo@dema.ufcg.edu.br
}

\begin{abstract}
RESUMO
O reaproveitamento de resíduos de borracha é de extrema importância atualmente, tanto para minimizar os efeitos nocivos no meio ambiente, quanto para reduzir o custo no desenvolvimento de novos materiais. Considerando que a maioria dos trabalhos relatados na literatura se refere ao reaproveitamento dos resíduos de pneus, o presente trabalho tem como objetivo avaliar a influência dos compatibilizantes SBS e SEBS-MA no desempenho da mistura de PS/resíduo de borracha da indústria de calçado (SBR), utilizando $5 \%$ em peso destes compatibilizantes. As misturas inicialmente foram preparadas em uma extrusora de rosca dupla corrotacional e, posteriormente, os grânulos extrudados moldados por injeção. Estas foram analisadas por ensaios de impacto, flexão, temperatura de deflexão térmica (HDT), termogravimetria (TG) e microscopia eletrônica de varredura (MEV). Os resultados evidenciaram que a utilização de qualquer um dos compatibilizantes na mistura PS/SBR aumentou expressivamente a resistência ao impacto, enquanto que as propriedades de flexão e HDT foram inferiores em relação à matriz polimérica. Em geral, ficou comprovado que o SBS é mais eficaz no processo de compatibilização do sistema PS/SBR, aumentando em 320\% a resistência ao impacto em relação ao PS, bem como tendo uma perda de apenas 10,9\% da HDT. Os resultados de termogravimetria ilustraram que a mistura PS/resíduo apresentou uma maior estabilidade térmica, em relação ao PS puro, para temperatura superior a $376^{\circ} \mathrm{C}$. As morfologias apresentadas pelas misturas ternária e binária foram bastante diferentes e típicas de misturas imiscíveis. Estes resultados mostram uma boa perspectiva de uso destes rejeitos industriais (SBR), uma vez que se pode valorizar um material que seria descartado. Além disso, tem a possibilidade de desenvolver um novo material com boas propriedades, bem como minimizar o efeito negativo desses rejeitos nos ecossistemas.
\end{abstract}

Palavras-chave: Tenacificação, reaproveitamento, resíduos de calçado, poliestireno, propriedades.

\section{ABSTRACT}

The reuse of rubber residue is extremely important nowadays, both to minimize the bad effects to the environment and to reduce the costs of new materials development. Seeing that, most of the reported papers in literature refer to the reuse of tire rubber, this work aims to evaluate the influence of SBS and SEBS-MA compatibilizers on the performance of PS/rubber residue (SBR) mixture from shoes industry, using 5\% wt. of these compatibilizers. The mixtures were initially prepared in a co-rotational twin screw extruder and the extruded pellets were later molded by injection. The samples were analyzed by impact, flexural, heat deflection temperature (HDT), thermogravimetry (TG) and scanning electron microscopy (SEM) experiments. The results evidenced that the use of any compatibilizers in the PS/SBR mixtures significantly 
increased the impact strength whereas the tensions and HDT properties were lower in relation to polymer matrix. It was proved that the SBS is more efficient in the compatibilizing process of PS/SBR system, increasing $320 \%$ the impact strength compared to PS, as well as having a $10.9 \%$ lost only in the HDT. The results of TG illustrated that the PS/residue mixture presented a higher thermal stability in relation to the pure PS, for temperature over $376^{\circ} \mathrm{C}$. The morphologies presented from ternary and binary mixtures were clearly different and typical of immiscible blends. The results showed a good perspective of this industries wastes (SBR) use, once it was possible to value a material that would be discharged. Besides, there is the possibility to develop a new material with good properties, as well as minimize the negative effect of these wastes in the environment.

Keywords: toughening, reuse, shoes residues, polystyrene, properties.

\section{INTRODUÇÃO}

Com o crescimento da população mundial, do avanço tecnológico e do aumento do poder de compra dos consumidores, as indústrias trabalham a todo vapor para suprir a demanda da população, e com isso crescem os problemas por elas causados, como na geração de resíduos prejudiciais ao meio ambiente [1]. Atualmente, destaca-se o crescente uso de materiais à base de polímeros, impulsionado pela diversidade de propriedades $\mathrm{e}$ características. Porém, o elevado consumo de materiais poliméricos contribui intensivamente, para o agravamento da deterioração do meio ambiente, pois estes materiais apresenta elevada resistência à degradação [2]. Neste contexto, um dos principais materiais nocivos ao meio ambiente é a borracha sintética.

Quando os resíduos de borracha são descartados no meio ambiente, tornam-se um inconveniente, principalmente devido à sua resistência a degradação [3]. O Brasil é o maior produtor e consumidor de borracha sintética da América Latina, sendo o setor automotivo o maior consumidor de elastômeros, seguido pelos calçados e eletroeletrônicos. O segundo maior consumidor de borracha é o setor calçadista, que ativamente recebe advertências como um dos maiores geradores de rejeitos industriais. Destaca-se na indústria de calçados o número excessivo de aparas que são geradas durante a etapa da construção inferior do calçado [4]. Dentre as borrachas sintéticas mais consumidas nas indústrias, destaca-se principalmente o copolímero aleatório de estireno-butadieno (SBR) [5].

O SBR é a borracha sintética mais utilizada no mundo, em decorrência da utilização na fabricação de pneus, além de grande quantidade de artefatos para o setor de calçados [6]. O copolímero de butadienoestireno (SBR) é um material apolar que apresenta boas propriedades, desempenho mecânico satisfatório e alta resistência ao envelhecimento, bem como compatibilidade com a maioria dos elastômeros [7]. Portanto, os rejeitos de borrachas das indústrias de pneus ou de calçados, quando descartados no meio-ambiente, promove uma agressão ao ecossistema, bem como é um desperdício de matéria-prima [8]. Atualmente, esta é uma das principais preocupações para a comunidade científica, bem como dos ambientalistas.

A questão do reaproveitamento de resíduos de borracha é de extrema importância, tanto em relação à diminuição dos efeitos negativos causados pelos rejeitos no meio ambiente, assim como, ao fato da conservação de energia, uma vez que as matérias-primas para a indústria da borracha em sua grande maioria são advindas do petróleo $[9,10]$. Entretanto, devido às borrachas possuírem ligações cruzadas, esses materiais não podem ser fundidos e remoldados com facilidade [11]. Para contornar esse problema, tem sido explorada a incorporação de borracha moída de pneu ou de calçado em polímeros virgens, ou seja, o desenvolvimento de misturas poliméricas [12]. A utilização de misturas físicas de polímeros pode ser uma alternativa para o reaproveitamento de resíduos de borracha com vantagens econômicas [13].

A mistura de polímeros constitui uma alternativa para obter materiais com características físicas, químicas e físico-químicas melhores do que aquelas dos polímeros puros, bem como se obtém materiais com propriedades específicas. Geralmente, os constituintes das misturas poliméricas são selecionados de modo a conservar as vantagens de cada polímero [14]. Além disso, outras vantagens para a utilização das misturas são: melhorar a processabilidade e/ou as propriedades; reduzir custo do produto; e reaproveitamento de resíduos poliméricos [15]. Um dos principais objetivos das misturas de termoplásticos com borrachas é a de promover a tenacificação de polímeros frágeis (PS, PMMA, etc). Com a tenacificação, um material frágil e rígido, pode se tornar um material dúctil, com uma alta resistência ao impacto [16]. Entretanto, os teores das composições das misturas devem ser equilibrados para se obter um balanço de propriedades.

A grande maioria das misturas de dois polímeros é imiscível, o que leva, com frequência, a um material com propriedades mecânicas inferiores. Para contornar este problema, utiliza-se um agente compatibilizante que atua na interface dos constituintes da mistura, promovendo uma diminuição da tensão interfacial e melhorando a dispersão [17]. A escolha adequada do agente compatibilizante pode levar a viabilidade do desenvolvimento de misturas com resíduos de borracha com boas propriedades. Sabe-se que 
os resíduos de borracha de pneus e calçados, geralmente são constituídos de uma mistura complexa de SBR, cargas, aditivos de processamento, agentes de cura e estabilizantes. Por isso, a possibilidade de reaproveitamento dos resíduos de borracha por meio de misturas mecânicas, bem como a possibilidade de agregar valor a um material que seria descartado da cadeia produtiva é uma justificativa para que se incentive a pesquisa da melhor combinação de termoplástico/resíduo de borracha/compatibilizante, ou seja, a busca pela otimização de propriedades. Alguns trabalhos já foram relatados na literatura sobre o desenvolvimento de misturas poliméricas a base de resíduos de borracha e termoplásticos.

FUHRMANN et al. [18] investigaram o reaproveitamento dos resíduos de borracha de pneu moído no desenvolvimento de blendas com várias matrizes de termoplásticos (PE, PP, PS, HIPS, PBT e PA6). Foi realizada uma análise nas propriedades mecânicas (resistência ao impacto e módulo de elasticidade sob tração). As blendas foram preparadas em uma extrusora de rosca dupla corrotacional e, posteriormente, moldadas por injeção. As blendas de resíduos de borracha de pneu/termoplástico (PBT, PA6, PP, PS e HIPS) foram preparadas nas proporções $0 / 100,0 / 90$ e $0 / 80 \%$ em peso para cada composição, enquanto a blenda resíduos de borracha de pneu/ PE nas proporções $0 / 100 ; 10 / 90 ; 20 / 80 ; 40 / 60$ e 60/40\% em peso. Os resultados evidenciaram que o módulo de elasticidade, tende a decair à medida que aumenta o teor de resíduos de pneu para todas as blendas. A resistência ao impacto tende a aumentar ou manter o valor da matriz pura para as blendas a base dos termoplásticos de PP, HIPS, PS e PBT, sendo que a blenda resíduo de borracha/PBT tem uma queda na resistência ao impacto em relação à matriz pura para a composição de $10 \%$ de resíduos de borracha. As blendas a base de PA6 tende a decair a resistência ao impacto à medida que aumenta o teor de borracha, provavelmente devido à diferença de polaridade entre matriz de PA 6/resíduos de borracha de pneu.

COSTA et al. [19] analisaram as propriedades e morfologia de misturas de PP/EPDM/Pó de pneu, sendo a borracha passada em peneiras 40 e 60 mesh respectivamente. As misturas foram processadas em uma extrusora de rosca dupla corrotacional e moldadas por injeção. Nesse estudo, foi realizada a metodologia da superfície de resposta (MSR) do comportamento mecânico de diferentes misturas ternárias de PP/EPDM/ Pó de pneu. Os resultados evidenciaram que valores elevados de resistência ao impacto são alcançados $(>80$ $\mathrm{J} . \mathrm{m}^{1}$ ) quando a mistura física de PP/EPDM/Pó de pneu mantém as proporções de EPDM e Pó de pneu em torno de $25 \%$. As propriedades mecânicas sob tração exibem um rápido declínio quando o percentual de partículas de borracha é aumentado nas misturas ternárias. A granulometria de 60 mesh das partículas de borracha produz um desempenho melhor. O EPDM auxilia na melhoria da adesão interfacial entre PP e as partículas de pó de pneu. A superfície de fratura da composição PP/EPDM/ Pó de pneu 50/25/25\% analisada por meio de microscópio eletrônico de varredura (MEV), exibe um pequeno número de vazios e uma melhor dispersão quando comparada com a de outras composições.

LUNA et al. [20] desenvolveram misturas de PS/SBR e PS/SBR/SBS, sendo a fase dispersa de SBR passada em peneira 40 mesh. As misturas binárias foram preparadas nas proporções em peso de 70/30, 60/40 e $50 / 50 \%$ e as ternárias nas proporções em peso de $67,5 / 27,5 / 5 ; 57,5 / 37,5 / 5$ e $47,5 / 47,5 / 5 \%$, bem como, as mesmas sendo processadas em uma extrusora de rosca dupla corrotacional, e posteriormente, os grânulos extrudados foram moldados por injeção. Ficou evidenciado que não houve perdas significativas da temperatura de deflexão térmica. As propriedades sob tração diminuíram em relação ao poliestireno. O ensaio de análise térmica dinâmica-mecânica (DMTA) evidencia a presença de dois picos de transição distintos, um referente à $\mathrm{Tg}$ do $\mathrm{PS}$ e o outro referente a $\mathrm{Tg}$ do polibutadieno $(\mathrm{PB})$. A morfologia ilustrou uma redução da quantidade de vazios e do tamanho das partículas quando a mistura foi compatibilizada com 5\% de SBS.

LUNA et al. [21] desenvolveram misturas de poliamida 6 com resíduos de borracha. As misturas binárias PA6/SBR foram preparadas nas proporções em peso $90 / 10$ e $80 / 20 \%$ e as misturas ternárias PA6/SBR/PE-g-MA, nas proporções em peso 87,5/7,5/5 e 77,5/17,5/5\%. As misturas foram processadas em uma extrusora dupla rosca corrotacional da Coperion ZSK $18 \mathrm{~mm}$, e posteriormente injetadas. Foram realizados estudos sobre reologia, temperatura de deflexão térmica (HDT), análise térmica dinâmicomecânica (DMTA) e espectroscopia na região do infravermelho com transformada de Fourier (FTIR). Os resultados obtidos com o estudo reológico mostraram que quanto maior a percentagem de SBR adicionado, maiores os valores de torque. As temperaturas de deflexão térmica das blendas reduziram pouco, quando comparadas à da poliamida 6. No ensaio de DMTA, as blendas binárias e ternárias tiveram deslocamento dos picos. Os resultados do FTIR evidenciaram que as bandas características da PA6 não foram modificadas pela presença do SBR e nem pelo aumento da percentagem nas blendas binárias, bem como a presença de PE-gMA nas blendas ternárias, evidenciou que os agrupamentos químicos não foram afetados.

ZHAO et al. [22] avaliaram a influência do compatibilizante SBS e do óleo aromático no desempenho de blendas de poliestireno de alto impacto (HIPS) com resíduos de borracha de SBR. As blendas foram 
preparadas por mistura mecânicas, e posteriormente avaliadas as propriedades mecânicas e morfológicas. Os resultados evidenciaram que a mistura combinada de SBS com óleo aromático na blenda de HIPS/resíduos de borracha melhorou de forma significativa as propriedades mecânicas. Ficou evidenciado que a composição de $9 \%$ de SBS, com $15 \%$ de óleo aromático otimizou os resultados, sendo observado um aumento de $220 \%$ no alongamento, bem como uma melhora no módulo de elasticidade. A morfologia demonstrou que a adição de SBS combinado com o óleo aromático promoveu uma melhor adesão interfacial, bem como reduziu a quantidade de vazios e o tamanho das partículas de borracha.

$\mathrm{Na}$ incorporação de resíduo de borracha em uma matriz polimérica, vários fatores podem afetar os resultados, tais como: granulometria da borracha, quantidade de borracha adicionada, teor de negro de fumo na borracha, tipo de termoplástico, adesão entre a matriz e a borracha moída, modificação da sequência de mistura e o tipo de compatibilizante [23,24].

O presente trabalho tem como objetivo avaliar a influência dos compatibilizantes SBS e SEBS-MA no desempenho da mistura de (PS/compatibilizante) contendo resíduos de borracha provenientes da indústria de calçados nas propriedades e morfologia.

\section{MATERIAIS E MÉTODOS}

\subsection{Materiais}

Como matriz polimérica foi utilizada o poliestireno cristal (PS) sob o código 158K Q611, IF= 4,5 g/10 min na forma de grânulos, fabricado pela Unigel S.A.

Foi utilizado como fase dispersa um resíduo de borracha de calçado (SBR), proveniente da indústria de calçados São Paulo Alpargatas S.A. da região de Campina Grande/PB. A formulação do composto é baseada em: cargas minerais, elastômero de butadieno e estireno, pigmentos, acelerantes, esponjantes, agentes de fluxo e agente de vulcanização. A composição parcial aproximada do resíduo é: $31 \%$ de SBR, $26,8 \%$ de $\mathrm{CaCO}_{3}, 21,5 \%$ de óleo, $7 \%$ de negro de fumo e $13,7 \%$ de massa residual.

Como compatibilizantes foram utilizados o copolímero tribloco linear (SBS) sob o código D1101 e o copolímero estireno-(etileno-butileno)-estireno enxertado com 1,7\% de anidrido maléico (SEBS-MA) sob código FG1901, IF = $5 \mathrm{~g} / 10$ min e baixo peso molecular na forma de grânulos, adquirido da Activas S.A.

\subsection{Métodos}

\subsubsection{Preparação das Misturas}

Antes da preparação das misturas a fase dispersa passou em uma peneira ABNT $\mathrm{N}^{\circ} 18(1 \mathrm{~mm})$. As misturas PS/SBR, na proporção de 50/50 \% e com 5\% de compatibilizante, foram processadas em uma extrusora de rosca dupla corrotacional da Coperion, ZSK $18 \mathrm{~mm}$, com temperatura de $190^{\circ} \mathrm{C}$ nas zonas 1 e 2 e $200^{\circ} \mathrm{C}$ nas demais zonas, velocidade de $250 \mathrm{rpm}$ e taxa de alimentação de $4 \mathrm{~kg} / \mathrm{h}$.

Para estudar o efeito dos copolímeros SBS e SEBS-MA na compatibilização da mistura PS/SBR por meio das propriedades, foram realizadas as sequências de misturas abaixo, bem como da mistura não compatibilizada:

1. PS/SEBS-MA + SBR - o PS é pré-misturado com o SEBS-MA em uma etapa de extrusão e, em seguida, granulado. A essa mistura foi adicionado o SBR em uma segunda etapa de extrusão.

2. PS/SBS + SBR - o PS é pré-misturado com o SBS em uma etapa de extrusão e, em seguida, granulado. A essa mistura foi adicionado o SBR em uma segunda etapa de extrusão.

3. $\mathrm{PS} / \mathrm{SBR}$ - todos os componentes foram misturados simultaneamente em uma única etapa de extrusão.

Para cada sequência de mistura abaixo foi utilizado um total de $2 \mathrm{~kg}$ de materiais distribuídos nas seguintes proporções:

1. PS/SEBS-MA + SBR $-(47,5 / 5+47,5) \%$ em peso

2. $\mathrm{PS} / \mathrm{SBS}+\mathrm{SBR}-(47,5 / 5+47,5) \%$ em peso

3. $\mathrm{PS} / \mathrm{SBR}-(50 / 50) \%$ em peso

Com o término do processamento de todas as sequências de misturas, os grânulos extrudados foram secos, em uma estufa a vácuo com temperatura de $60^{\circ} \mathrm{C}$ durante 48 horas. Após a secagem, os grânulos 
extrudados foram moldados por injeção na forma de corpos de prova para ensaios de impacto Izod (ASTM D256), flexão (ASTM 790) e HDT (ASTM D648). Os corpos de prova foram moldados em uma injetora Fluidmec, na temperatura de $180^{\circ} \mathrm{C}$ na zona 1 e $190^{\circ} \mathrm{C}$ na zona 2 , temperatura do molde de $40^{\circ} \mathrm{C}$ e ciclo de injeção de 25 s. A Figura 1 apresenta um esquema do processamento das misturas, bem como, os corpos de provas injetados.

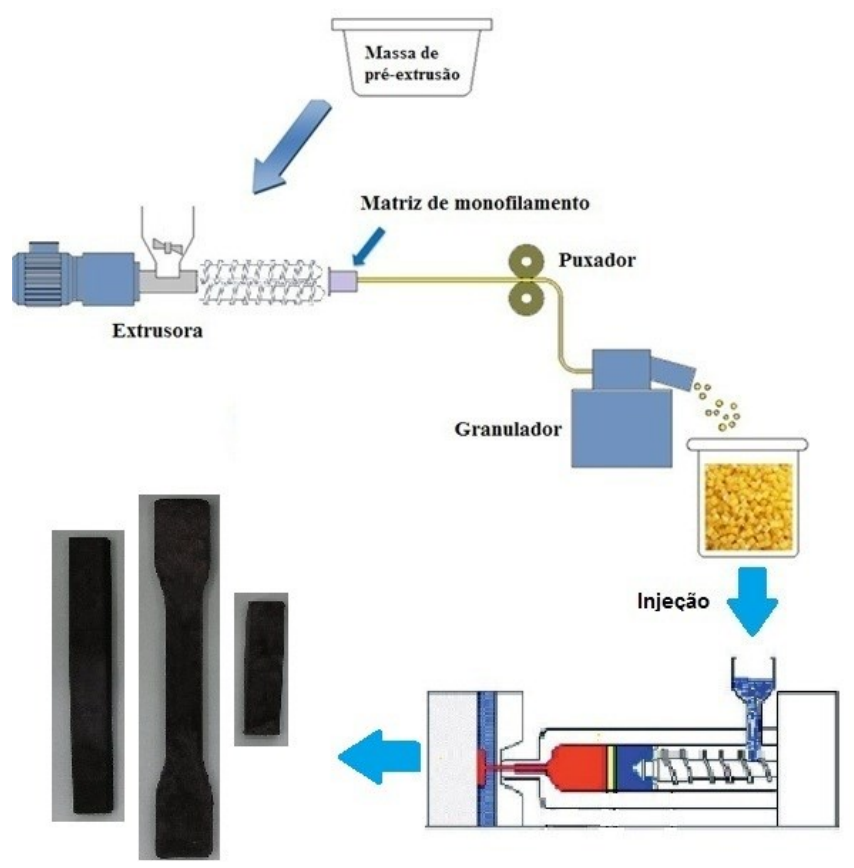

Figura 1: Esquema do processo de extrusão e injeção, bem como, o perfil da rosca utilizado na extrusora rosca dupla corrotacional. Fonte: ADAPTADO de FLEMING et al. [25]

\section{TÉCNICAS DE CARACTERIZAÇÃO}

\subsection{Ensaio de impacto}

O ensaio de impacto Izod foi realizado em 10 corpos de prova entalhados segundo a norma ASTM D256, em um aparelho da marca Ceast modelo Resil 5,5 J, operando com martelo de 2,75 J em temperatura ambiente.

\subsection{Ensaio de Flexão}

Os testes sob flexão foram conduzidos em uma máquina universal de ensaio da Shimadzu com capacidade de $50 \mathrm{kN}$, segundo a norma ASTM D790, operando em modo de compressão a uma velocidade de 1,6 mm/min e separação entre os apoios de $64 \mathrm{~mm}$. Os resultados foram analisados com uma média de 6 corpos de prova.

\subsection{Ensaio de temperatura de deflexão térmica (HDT)}

A temperatura de deflexão térmica (HDT) foi obtida, conforme a norma ASTM D648, em um equipamento Ceast, modelo HDT 6 VICAT, com uma tensão de $1,82 \mathrm{MPa}$, taxa de aquecimento de $120^{\circ} \mathrm{C} / \mathrm{h}$ (método A). A temperatura foi determinada após a amostra ter defletido $0,25 \mathrm{~mm}$. Uma série de seis amostras foi ensaiada e a temperatura de deflexão térmica medida.

\subsection{Termogravimetria (TG)}

As análises de termogravimetria foram obtidas em equipamento da TA Instruments SDT-Q600 Simultaneous TGA/DSC/DTA, na faixa de temperatura de $23^{\circ} \mathrm{C}$ a $500^{\circ} \mathrm{C}$, com razão de aquecimento de $10^{\circ} \mathrm{C} / \mathrm{min}$, sob atmosfera de nitrogênio, fluxo de $50 \mathrm{~mL} / \mathrm{min}$ em cadinho de alumina. 


\subsection{Microscópio eletrônico de varredura (MEV)}

As análises por microscopia eletrônica de varredura (MEV) foram realizadas na superfície de fratura dos corpos de prova submetidos ao ensaio de impacto. Foi utilizado um microscópio eletrônico de varredura, Shimadzu SSX-550 Superscan, a uma voltagem de $15 \mathrm{kV}$, sob alto vácuo e as superfícies de fratura dos corpos de prova foram recobertas com ouro.

\section{RESULTADOS E DISCUSSÃO}

\subsection{Ensaio de impacto}

A Figura 2 ilustra os valores de resistência ao impacto das amostras de PS, da mistura binária e das ternárias, bem como a tendência destas com os diferentes compatibilizantes.

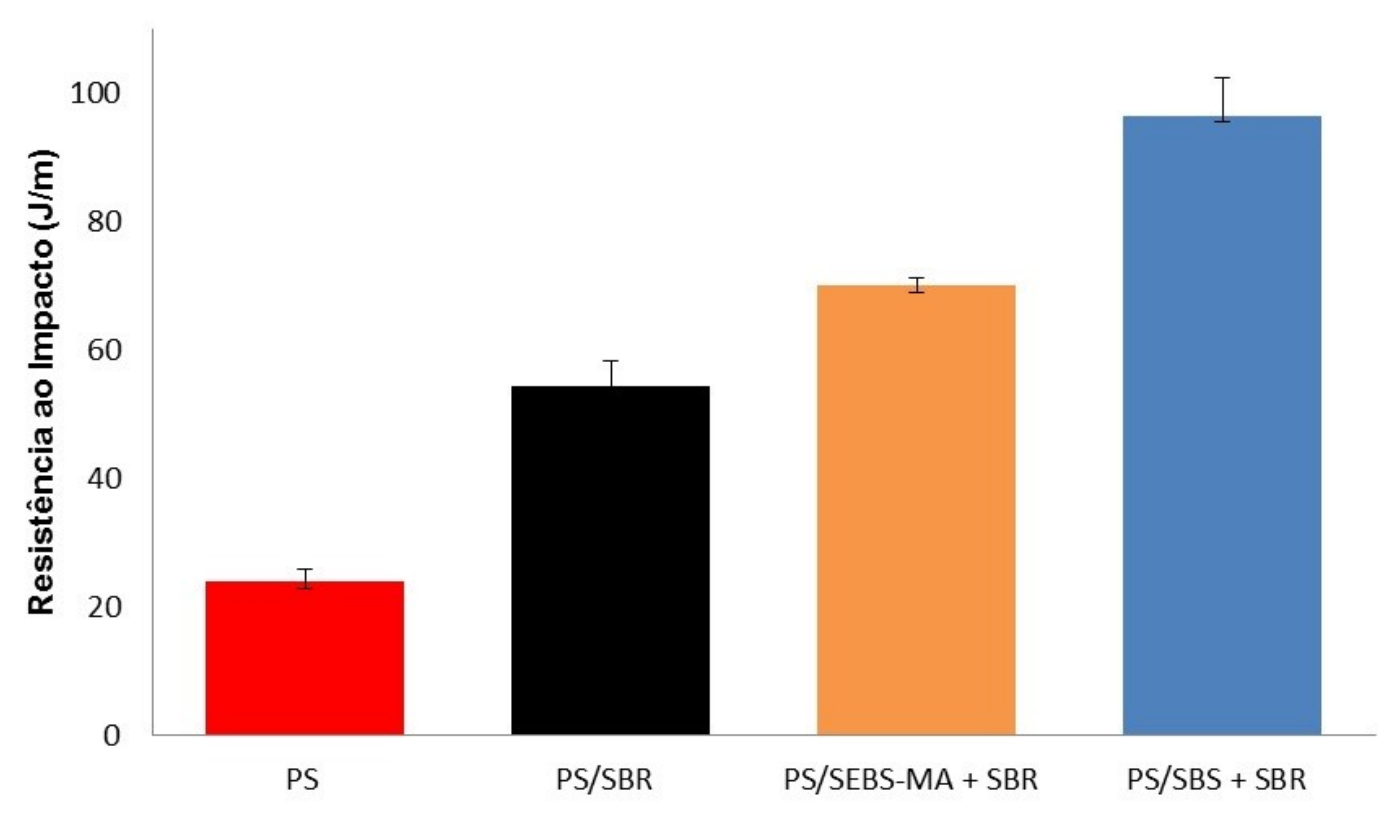

Figura 2: Resistência ao impacto dos materiais.

Conforme a Figura 2 observa-se que o PS apresentou a mais baixa resistência ao impacto em torno de $23,8 \mathrm{~J} / \mathrm{m}$, o que já era previsível por se tratar de um polímero frágil. A mistura direta de poliestireno com o resíduo de borracha (PS/SBR) promoveu uma melhoria da resistência ao impacto, isto é, a fase borrachosa auxilia na tenacificação da matriz.

Na Figura 2, observa-se que a resistência ao impacto da mistura binária PS/SBR aumentou substancialmente em relação à matriz de PS, correspondendo a $138 \%$ de aumento. Este aumento pode ser atribuído ao fato das partículas de borracha quando misturada ao poliestireno, induz os mecanismos de tenacificação, como o microfibrilamento no material, que ocorre ao redor do equador das partículas presentes, promovendo uma distribuição de tensões e, portanto, possibilita-se uma dissipação significativa da energia aplicada antes da geração das trincas [26]. Porém, constata-se que a mistura binária teve propriedades de impacto inferior às misturas compatibilizadas. Tal fato é devido à insuficiente adesão entre as duas fases de PS e SBR, bem como, a coalescência das partículas de borrachas como se observa na Figura $9 \mathrm{~b}$.

Geralmente, a adição de um compatibilizante em uma mistura binária é conduzida de forma a se obter uma mistura mais homogênea e uma morfologia da fase secundária mais adequada [27].

Nota-se na Figura 2, que a sequência de mistura PS/SBS + SBR, foi a mais eficaz no processo de tenacificação, com um aumento de $320 \%$ na resistência ao impacto, em relação à matriz de PS, enquanto a sequência PS/SEBS-MA + SBR aumentou 207\%. Analisando-se os resultados das misturas ternárias, observa-se que a adição de apenas 5\% de SBS e SEBS-MA nas misturas PS/SBS + SBR e PS/SEBS-MA + 
SBR resultou na produção de misturas com energia de impacto bem superior em relação à mistura binária. Estes resultados confirmam que as sequências de mistura influenciam nas propriedades do material e que dependendo da escolha do compatibilizante tem-se melhor compatibilidade. Porém, pode-se enfatizar a eficácia da utilização de ambos os copolímeros na compatibilização desses sistemas. Possivelmente o SBS e o SEBS-MA atuaram melhorando a interface, proporcionando uma maior adesão entre as fases vítrea e borrachosa e, permitindo assim maior transferência de energia mecânica de impacto da matriz para a fase dispersa [28].

De acordo com a Figura 2, nota-se que a sequência PS/SBS + SBR aumentou 37\% em relação a PS/SEBS-MA + SBR. Esta menor eficiência do compatibilizante SEBS-MA em relação ao SBS, possivelmente pode ser atribuído à diferença de polaridade entre os constituintes do sistema. Esta diferença de polaridade não favoreceu ao sistema, provavelmente porque ambos os polímeros (PS e SBR) não dispõem de grupos funcionais em suas estruturas moleculares que possam reagir com o anidrido maleico (MA), estabilizando a interface.

\subsection{Ensaio sob flexão}

As Figuras 3 e 4 evidenciam os valores de resistência sob flexão e do módulo de elasticidade do PS, da mistura binária e das ternárias, bem como, a tendência destas com os diferentes compatibilizantes.

Conforme as Figuras 3 e 4 observa-se que a presença de SBR nas misturas alterou drasticamente as propriedades de resistência sob flexão e rigidez em relação à matriz de PS. Nota-se que, em geral, todos os valores da resistência sob flexão e do módulo de elasticidade das misturas ternárias e binária foram abaixo daqueles obtidos para o PS puro. Este decaimento das propriedades das misturas em relação à matriz de PS está relacionado ao fato das partículas dispersas serem elastoméricas e, consequentemente, aumentam a flexibilidade da cadeia [29, 30]. Por outro lado, a boa resistência à tração do PS está associada com sua estrutura molecular, pois o grupo lateral benzênico presente no PS restringe a mobilidade molecular e eleva a temperatura de transição vítrea $\left(\cong 100^{\circ} \mathrm{C}\right)$, fazendo-se necessária alta carga de flexão para provocar a ruptura do material [31].

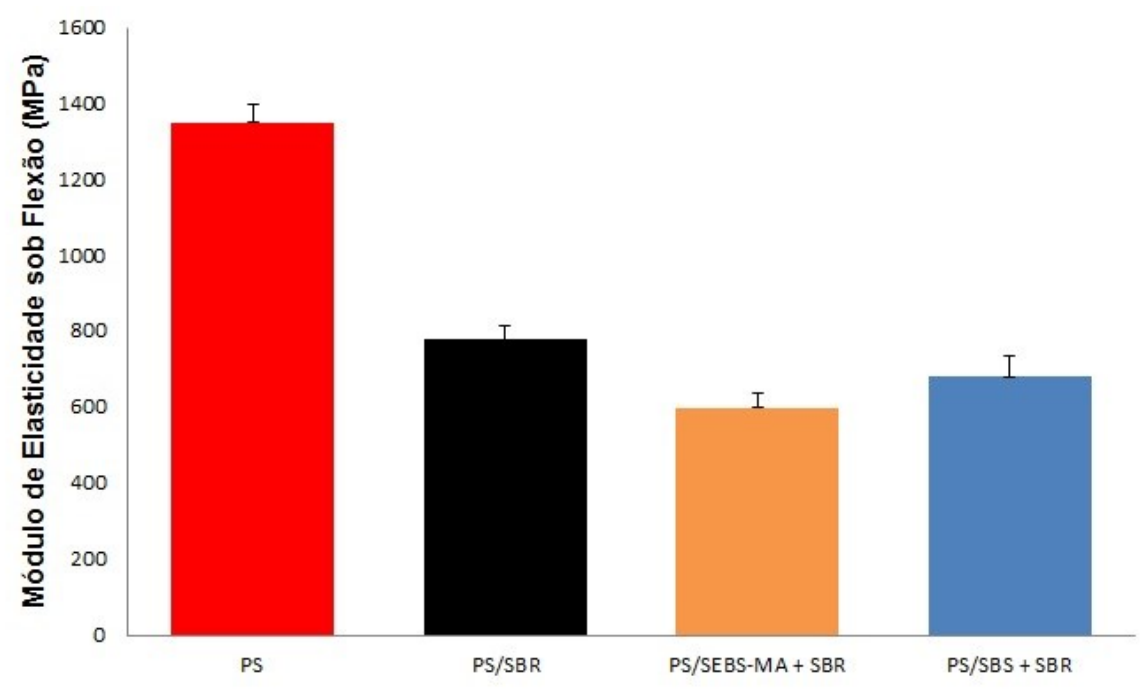

Figura 3: Resistência sob flexão dos materiais.

Verifica-se na Figura 3 que os agentes de compatibilização apresentaram um efeito negativo nas propriedades sob flexão das misturas em relação à mistura não compatibilizada PS/SBR (50/50\%), efeito que foi mais pronunciado na mistura compatibilizada com SBS. Conforme a Figura 3 é possível observar que, fazendo uso de SEBS-MA, houve um decréscimo de 10,3\% no valor da resistência sob flexão, enquanto o SBS diminuiu 20,1\% na resistência sob flexão quando comparada com a mistura binária.

TANG el al. [32] reportaram que o PS tenacificado com elastômero, sob ação de uma tensão, sofre alteração no estado de tensão da fase matricial levando a concentração ou dissipação dessa energia pelas partículas elastoméricas constituintes da fase dispersa. Portanto, quanto menor o valor da tensão apresentada 
pela mistura durante o ensaio, mais energia foi dissipada pelo material. Tal fato é corroborado pela Figura 2, onde se verifica que o sistema PS/SBS + SBR apresentou a maior resistência ao impacto, ou seja, houve um maior nível de dissipação de energia neste sistema.

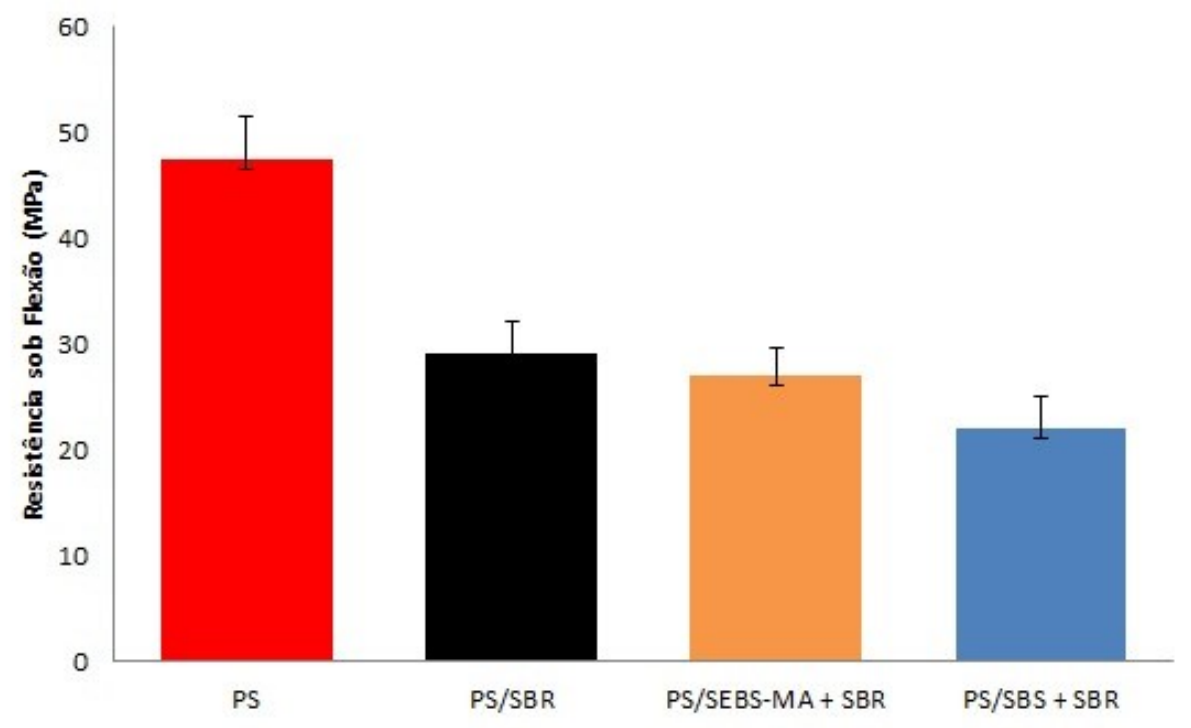

Figura 4: Módulo de elasticidade sob flexão dos materiais.

Conforme se pode observar na Figura 4, houve uma redução nos valores do módulo de elasticidade sob flexão para as misturas compatibilizadas em relação ao da mistura não compatibilizada. A introdução de $5 \%$ do SBS no sistema PS/SBR acarretou uma diminuição do modulo de elasticidade em 10,9\%, enquanto o uso do SEBS-MA proporcionou à mistura uma redução de $24,6 \%$ quando comparada a mistura binária. Provavelmente, o melhor desempenho do compatibilizante SBS comparado ao SEBS-MA com relação ao módulo de elasticidade sob flexão, pode estar relacionado ao bloco central do SBS que é constituído por unidades de instauração derivada do butadieno, que são mais semelhantes quimicamente às cadeias do SBR, e consequentemente promovendo uma melhor interação entre os constituintes do sistema PS/SBS + SBR. Além disso, o grupo MA presente no compatibilizante SEBS-MA é polar, e deve levar a uma menor interação física entre os constituintes da mistura, promovendo menores valores nas propriedades.

\subsection{Ensaio de temperatura de deflexão térmica (HDT)}

A Figura 5 evidencia os resultados obtidos para a temperatura de deflexão térmica do PS, da mistura binária e das ternárias, bem como, a tendência destas com os diferentes compatibilizantes.

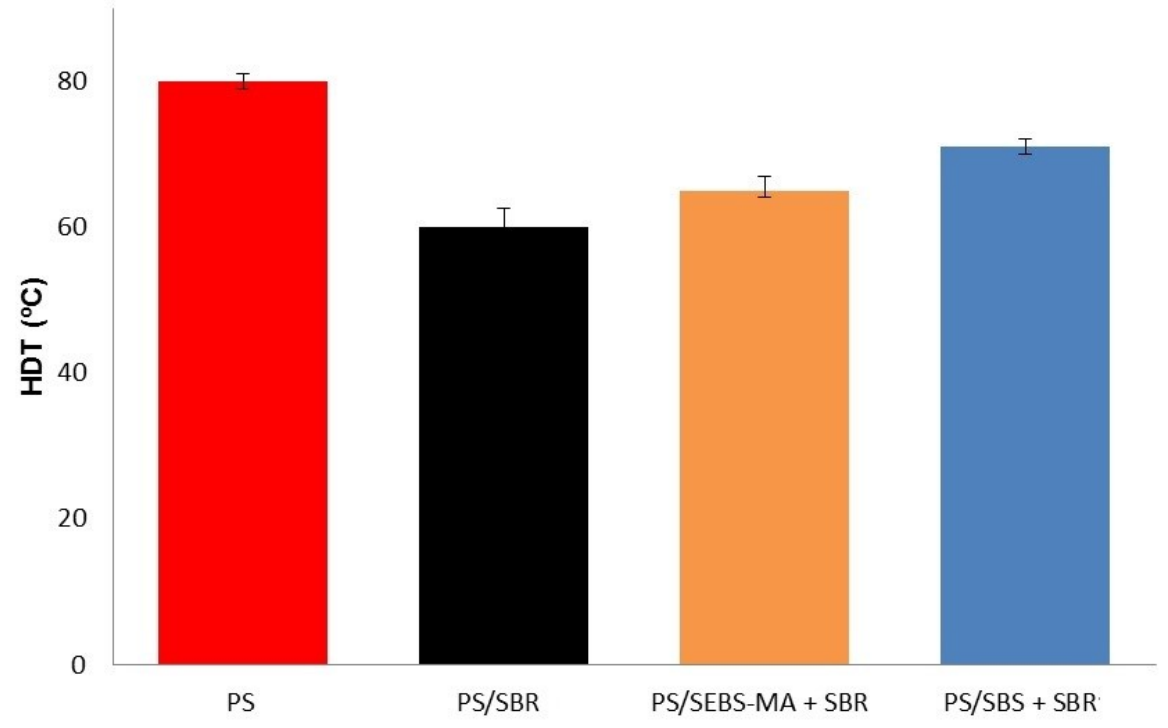

Figura 5: Temperatura de deflexão térmica dos materiais. 
Verifica-se na Figura 5 que o valor máximo para a HDT foi de $79,7^{\circ} \mathrm{C}$ para o PS e o menor valor de $60^{\circ} \mathrm{C}$ para a mistura binária PS/SBR (50/50\%). Fica evidenciado na Figura 5 que todas as misturas apresentaram uma temperatura de deflexão térmica abaixo do PS. Tal fato pode ser atribuído ao fato do PS ser caracterizado como um material rígido e, necessitando de uma maior temperatura para que o corpo de prova sofra deflexão.

GRASSI e FORTE [33] reportaram em seus estudos que a temperatura de deflexão térmica não sofre modificação com a maioria das variáveis, mas somente com o aumento do teor de borracha. Afinal, a HDT é uma propriedade que depende mais significativamente da fase contínua, que é responsável pela rigidez do material.

Verifica-se que a adição de SBR ao PS diminuiu a HDT do mesmo, e também que 50\% de SBR na mistura binária provocou uma queda no valor da HDT de $25 \%$, quando comparado ao PS. Isso pode ser devido ao fato do SBR ser um elastômero que apresenta alta flexibilidade, devido ao seu alto valor de butadieno $(>70 \%$ ) [6], e consequentemente atua tornando o sistema PS/SBR mais flexível, gerando com isso uma perda no comportamento da HDT.

Verifica-se na Figura 5 que os agentes de compatibilização promoveram um efeito positivo nas propriedades de HDT das misturas ternárias em relação à mistura não compatibilizada PS/SBR (50/50\%), efeito que foi mais pronunciado na mistura compatibilizada com SBS. Porém, os valores da HDT das misturas ternárias continuam abaixo do PS. Conforme a Figura 5, é possível observar que fazendo uso de SEBS-MA, houve um aumento de $8 \%$, e com o SBS um aumento de $18 \%$ na HDT quando comparada com a mistura binária. $\mathrm{O}$ valor observado para a mistura PS/SBS $+\mathrm{SBR}\left(\sim 71^{\circ} \mathrm{C}\right)$ é muito interessante do ponto de vista tecnológico, pois ela teve uma queda de apenas 10,9\% da HDT quando comparada ao PS, bem como, um aumento de aproximadamente $320 \%$ na tenacidade, sendo que a mesma foi produzida com $47,5 \%$ de resíduos de calçados.

\subsection{Termogravimetria (TG)}

A Figura 6 apresenta os resultados de termogravimetria (TG/DTG), onde a perda de massa é registrada em função da temperatura do PS, da mistura binária PS/ SBR e das ternárias com 5\% de compatibilizante. O pico presente na curva de DTG das amostras é, fisicamente a temperatura na qual a perda de massa é máxima.
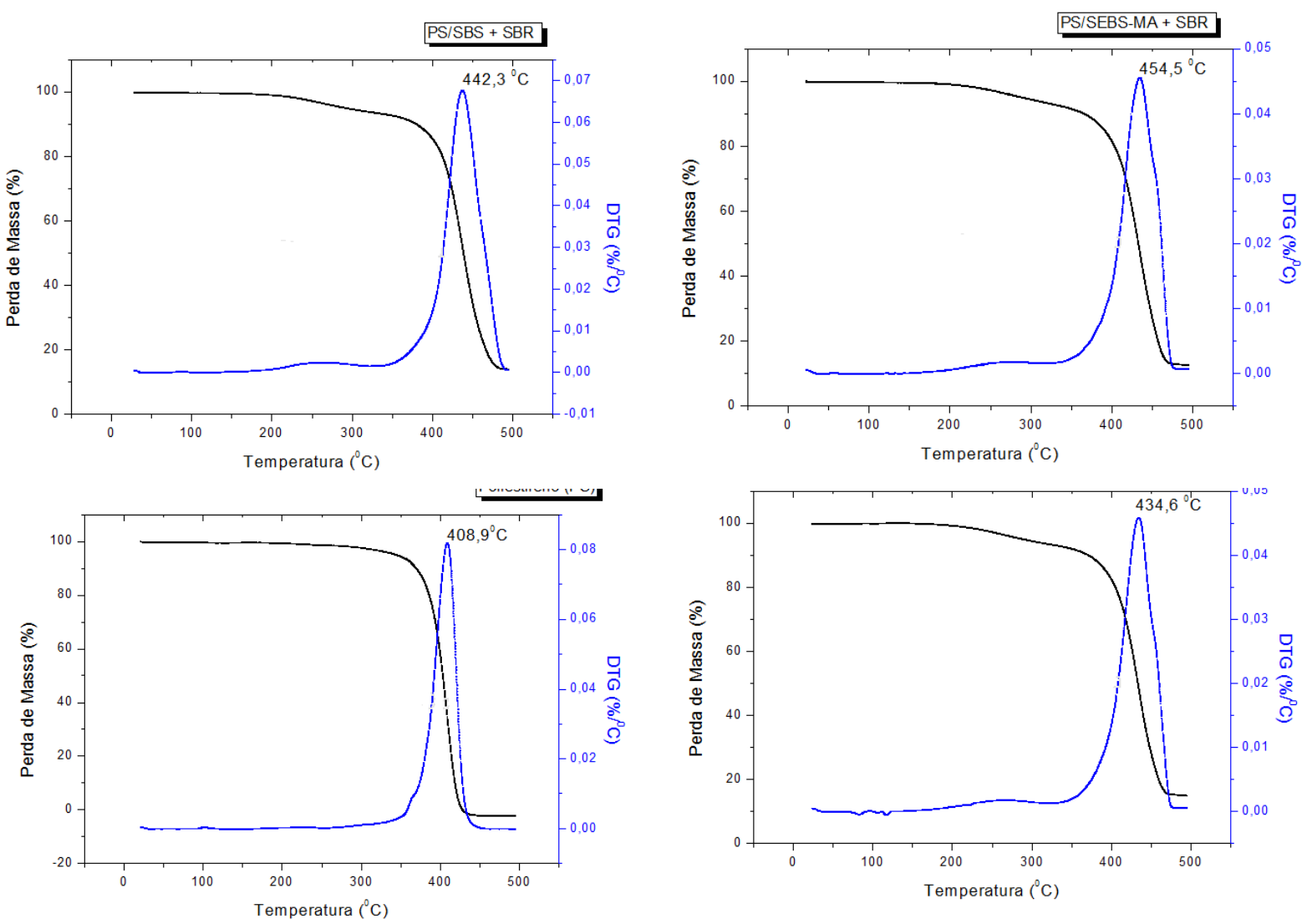

Figura 6: Curvas TG/DTG do poliestireno, da mistura binária e ternária com $5 \%$ de compatibilizante obtidas sob atmosfera de $\mathrm{N}_{2}$, a $10^{\circ} \mathrm{C} / \mathrm{min}$ e $\mathrm{m}=5 \mathrm{mg}$. 
A Figura 6 evidencia que o PS é termicamente estável no intervalo aproximado de temperatura entre $30^{\circ} \mathrm{C}$ e $350^{\circ} \mathrm{C}$, ou seja, não houve perda de massa significativa nessa faixa de temperatura. A partir desta temperatura de $350^{\circ} \mathrm{C}$ até $422^{\circ} \mathrm{C}$ há uma diminuição de $94,3 \%$ da massa do PS, estágio no qual ocorre a degradação do material ou o processo de ruptura de ligações primárias devido à energia térmica.

Observa-se na Figura 6 que em todas as misturas testadas não foram verificadas perdas de massa na faixa de temperatura entre $25^{\circ} \mathrm{C}$ até $229^{\circ} \mathrm{C}$, indicando que os materiais não apresentaram quantidades significativas de umidade ou outras substâncias voláteis nesta faixa de temperatura. Porém, pode-se constatar que na faixa de temperatura entre 230 até $350^{\circ} \mathrm{C}$, as misturas apresentam uma estabilidade térmica menor que o poliestireno e a curvas apresentaram um leve decréscimo. A Tabela 1 evidencia a origem da perda de massa das misturas na faixa de 230 até $350^{\circ} \mathrm{C}$.

Tabela 1: Origem da perda de massa das misturas ternárias e binária.

\begin{tabular}{c|c|l}
\hline \multicolumn{1}{c|}{ Material } & Temperatura $\left({ }^{\circ} \mathbf{C}\right)$ & \multicolumn{1}{c}{ Origem da Perda } \\
\hline PS/SBR & 230 até $350^{\circ} \mathrm{C}$ & $\begin{array}{l}\text { Plastificantes, antidegradantes, } \\
\text { aceleradores, auxiliares de } \\
\text { processo, ácido esteárico e } \\
\text { óleos extensores. }\end{array}$ \\
\hline PS/SEBS-MA + SBR & & \\
\hline
\end{tabular}

As Figuras 7 e 8 ilustram a combinação das curvas de perda de massa e DTG para as amostras de PS, das misturas ternárias e binária.

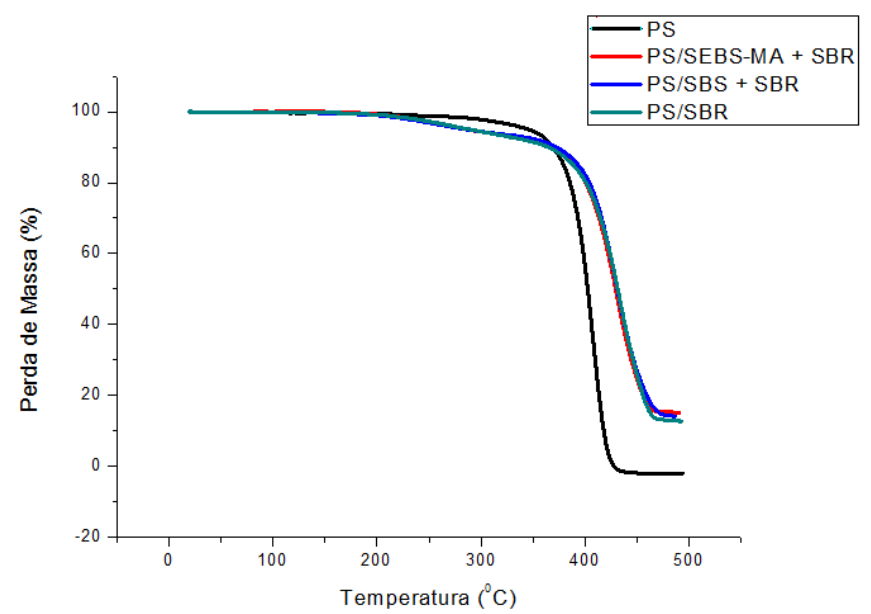

Figura 7: Curvas TG combinadas de perda de massa do PS, das misturas ternárias e binária.

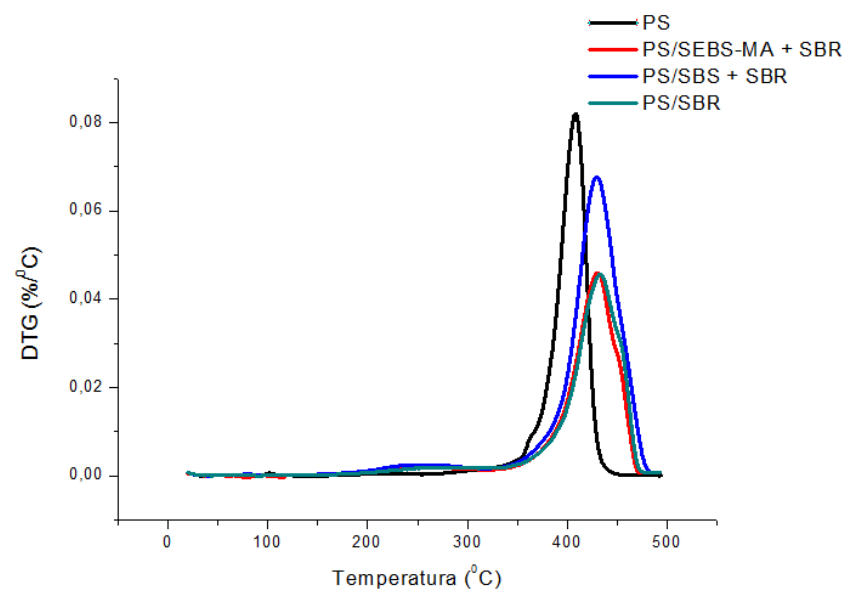

Figura 8: Curvas DTG da primeira derivada em relação a temperatura para o PS, as misturas ternária e binária. 
A Figura 7 ilustra que com a adição de elastômero ao PS, a temperatura de decomposição aumentou, proporcionando uma maior estabilidade térmica aos materiais para temperaturas superiores a $376^{\circ} \mathrm{C}$. Este efeito foi mais pronunciado para as blendas compatibilizadas. Porém, observa-se que a mistura PS/SBS + SBR apresentou uma pequena diminuição da temperatura de decomposição, quando comparada à mistura PS/SEBS-MA + SBR, provavelmente provocada pelo aumento da fase estirênica do material.

Observa-se na Figura 8 um deslocamento dos picos referentes às misturas para maiores temperaturas em relação ao PS. Ao mesmo tempo, pode-se notar que não há uma modificação perceptível no mecanismo de degradação térmica da mistura com ou sem compatibilizante, pois as curvas da primeira derivada são praticamente idênticas no seu formato. Nota-se na Figura 8 que o poliestireno apresenta um aspecto mais simétrico na curva da primeira derivada quando comparada as misturas, sendo a maior assimetria para a mistura PS/SEBS-MA + SBR.

$\mathrm{Na}$ temperatura de $500^{\circ} \mathrm{C}$, o PS não deixou resíduo, porém as misturas apresentaram. Os valores encontrados nestas misturas podem estar relacionados com a presença de inorgânicos e cargas minerais de enchimento em formulações de solados de calçados [34-36].

\subsection{Microscopia eletrônica de varredura (MEV)}

A Figura 9 ilustra as fotomicrografias obtidas por MEV do PS, da mistura binária PS/SBR e das ternárias com 5\% de SEBS-MA e SBS, respectivamente. As fotomicrografias estão com um aumento de 500x.
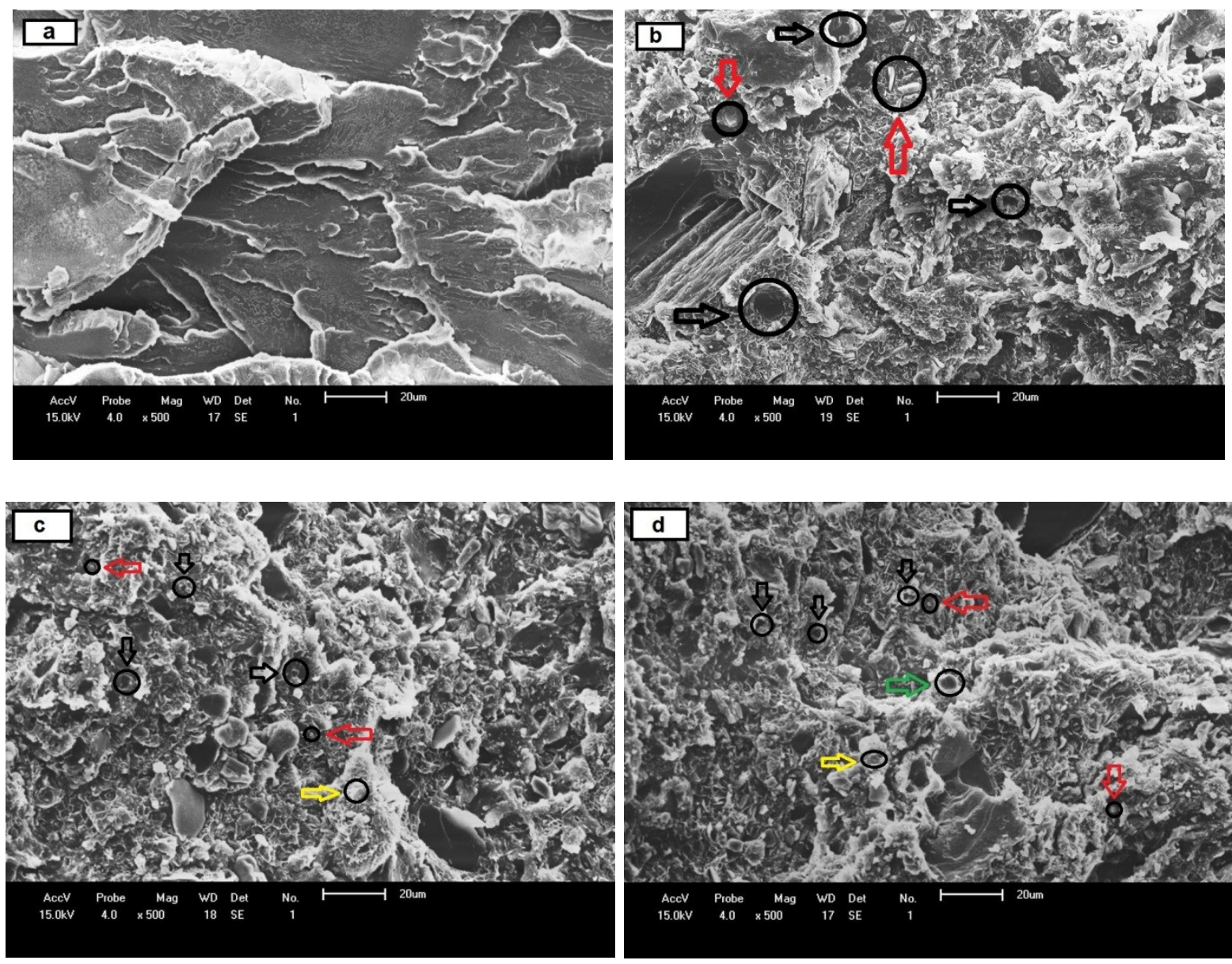

Figura 9: Fotomicrografias obtidas por MEV: (a) PS; (b) PS/SBR; (c) PS/SEBS-MA + SBR e (d) PS/SBS + SBR.

A Figura 9 apresenta a fotomicrografia do PS com um aspecto liso e homogêneo, que está associada à natureza frágil deste polímero de baixa tenacidade. Além disso, observam-se estrias correspondentes às marcas e degraus deixados pelas trincas responsáveis pela ruptura do corpo de prova e que foi nucleada a partir do entalhe [37]. Nota-se que praticamente não existe deformação plástica, bem como característica de uma trinca instável no qual se propaga rapidamente. 
Conforme a Figura 9b, a mistura PS/SBR apresenta espaços vazios entre as fases (setas pretas), o que indica uma fraca adesão entre a fase dispersa e a fase contínua, caracterizando um sistema incompatível. A má adesão ocorre devido à alta tensão interfacial existente entre os componentes, o que torna a interface com baixa resistência [38]. De fato, como pode-se verificar na Figura 9b, várias partículas foram sacadas totalmente da matriz. A incompatibilidade entre a matriz e a fase dispersa, visualizada através da morfologia da superfície de fratura, corrobora com os resultados de resistência ao impacto desse sistema, que foi inferior àqueles dos sistemas compatibilizados. Além disso, visualizam-se domínios de SBR alongados, largos e com baixa adesão interfacial (setas vermelhas).

Nota-se na Figura 9 (c,d) que o teor de 5\% dos compatibilizante SBS e SEBS-MA promoveu uma diminuição dos domínios das partículas de borracha (setas vermelhas) e dos vazios (setas pretas) em relação à mistura binária. Esse efeito pode acontecer devido à difusão e habilidade do compatibilizante em permanecer na interface entre as fases dos constituintes, promovendo uma redução da energia interfacial e evitando o coalescimento das partículas [39]. Na Figura 9 (c,d), está mostrado (setas amarelas) que a adesão entre as fases foi boa, pois observam-se partículas esféricas rompidas no plano, evidenciando que a interface não rompeu e confirmando que a adesão entre as fases foi aumentada em relação ao sistema sem compatibilizante.

A Figura 9d da mistura PS/SBS + SBR resultou em uma redução do tamanho dos domínios dispersos de SBR, assim como uma distribuição de tamanho das partículas de borracha. Segundo ALFARRAJ e NAUMAN [40], a bimodalidade da distribuição de tamanhos das partículas de borrachas favorece uma melhor tenacificação. Portanto, essa fotomicrografia 9d, confirma os melhores resultados de resistência ao impacto dentre todas as misturas. Além disso, observa-se a forte adesão interfacial da matriz de PS com as partículas de borracha (seta verde).

Aparentemente, a mistura preparada pela sequência PS/SEBS-MA + SBR (Figura 9c) resultou em uma redução mais acentuada do tamanho dos domínios dispersos de SBR (setas vermelhas). Embora essa mistura tenha tido uma melhor redução de partículas de borracha que a mistura PS/SBS + SBR, este sistema não apresentou um melhor resultado de resistência ao impacto, uma vez que o valor obtido foi menor que o valor encontrado para a mistura PS/SBS + SBR (Figura 2). Os estudos de ZHU et al. [41] evidenciam que existe um limite de tamanho crítico superior e inferior, além do qual as partículas de borracha não são eficientes para a tenacificação. Segundo os autores, partículas abaixo de um certo limite são incapazes de cavitar, e assim não participam do mecanismo de tenacificação. Talvez esta seja uma possível causa da menor tenacidade apresentada pela mistura PS/SEBS-MA + SBR quando comparada a PS/SBS + SBR.

\section{CONCLUSÕES}

Misturas de PS/resíduos de borracha (SBR) foram produzidas com os compatibilizantes SBS e SEBS-MA. O SBS foi mais eficaz no processo de compatibilização do sistema PS/SBR, aumentando em $320 \%$ a resistência ao impacto em relação ao PS. Os resultados do ensaio de flexão evidenciaram que, no geral, o módulo de elasticidade e a resistência sob flexão de todas as misturas reduziram quando comparados ao PS. O valor observado para a mistura PS/SBS + SBR é muito interessante do ponto de vista tecnológico, pois ela teve uma queda de apenas $10,9 \%$ da HDT quando comparada ao PS, bem como, um aumento elevado na tenacidade. A termogravimetria revelou que quando o resíduo de borracha foi incorporado às misturas, proporcionado uma maior estabilidade térmica aos materiais para temperaturas superiores a $376^{\circ} \mathrm{C}$. As morfologias apresentaram aspectos típicos de misturas imiscíveis. Em geral, o compatibilizante SBS é o mais eficaz para aumentar a compatibilidade do sistema PS/SBR, provavelmente por apresentar uma maior semelhança na estrutura molecular com as cadeias do SBR, e consequentemente promovendo uma melhor interação, enquanto o SEBS-MA por ser polar não favorece a interação física entre o sistema PS/SBR. Considerando todas as dificuldades inerentes para reaproveitar os resíduos de borracha, os resultados evidenciam que é possível obter um material com boas propriedades, bem como promover a redução de custos de produção. Além disso, evitam-se gastos com incineração e descartes em aterros sanitários. Sabe-se que na composição dos resíduos de borrachas podem conter estabilizantes, retardantes de chama e plastificantes que possuem baixa massa molar, possibilitando com o tempo a migração para solo e lençóis freáticos contaminando-os. Portanto, tanto a questão ambiental, quanto a redução de custos são justificativas para reaproveitar esses resíduos, bem como, a possibilidade de valorizar um resíduo que iria ser descartado. 


\section{AGRADECIMENTOS}

Os autores agradecem a UFCG/CNPq (Coordenação de Aperfeiçoamento de Pessoal de Nível Superior) pela concessão da bolsa de estudo do PIBIC, bem como, a Activas S.A., MCTI/CNPq e a São Paulo Alpargatas/PB pelo fornecimento das matérias primas.

\section{BIBLIOGRAFIA}

[1] SPINACÉ, M. A. S., DE PAOLI, M. A. “A tecnologia da reciclagem de polímeros”, Química Nova, v. 28, n. 1, pp. 65-72, 2005.

[2] SIDDIQUI, M. N., REDHWI, H. H. "Pyrolysis of mixed plastics for the recovery of useful products", Fuel Processing Technology, v. 90, n. 4, pp. 545-552, 2009.

[3] FIGUEIREDO, A. L., ALVES, A. P. M., JÚNIOR, V. J. F., et al., "Reciclagem terciária do poli(etileno tereftalato) visando a obtenção de produtos químicos e combustível: uma revisão", Revista Virtual de Química, v. 7, n. 4, pp. 1145-1162, 2015.

[4] FERREIRA, C. A., SERRANO, C. L. R., KUYVEN, P. S. "Use of analysis of variance and linear regression as prediction tool for mechanical performance of SBR", Plastics, Rubber and Composites, v. 40, n. 1, pp. 40-45, 2011.

[5] ZHAO, J., GHEBREMESKEL, G. N. "A Review of Some of the Factors Affecting Fracture and Fatigue in SBR and BR Vulcanizates", Rubber Chemistry and Technology, v. 74, n. 3, pp. 409-427, 2001.

[6] GRISON, E. C., BECKER, E., SARTORI, A. Borrachas e seus aditivos: componentes, influência e segredos, 1 ed., Porto Alegre, Suliani, 2010.

[7] COELHO, D. B., MARIANO, R. M., ZINE, C. L. G., et al., "Misturas NR/SBR: influência da ordem de adição dos aditivos da mistura e do tipo de carga sobre propriedades mecânicas", Polímeros: Ciência e Tecnologia, v. 21, n. 3, pp. 204-209, 2011.

[8] ARAÚJO, E. M., CARVALHO, L. H., FOOK, M. V. L., et al., "Propriedades mecânicas de blendas de PS/resíduo de borracha - Influência da concentração, granulometria e método de moldagem", Polímeros: Ciência e Tecnologia, v. 7, n. 3, pp. 45-52, 1997.

[9] FANG, Y., ZHAN, M., WANG, Y. "The status of recycling of waste rubber”, Material \& Design, v. 22, n. 2, pp. 123-128, 2001.

[10] ADHIKARI, B., DE, D., MAITI, S., "Reclamation and recycling of waste rubber", Progress in Polymer Science, v. 25, n. 7, pp. 909-948, 2000.

[11] WEBER, T., ZANCHET, A., CRESPO, J. S., et al., "Caracterização de artefatos elastoméricos obtidos por revulcanização de resíduo industrial de SBR (copolímero de butadieno e estireno)", Polímeros: Ciência e Tecnologia , v. 21, n. 5, pp. 429-435, 2011

[12] BOONDAMNOEN, O., OHSHIMA, M., AZURA. A.R., et al., "Recycling waste natural rubber latex by blending with polystyrene characterization of mechanical properties", International Journal of Modern Physics: Conference Series, v.6, n.2, pp. 391-396, 2012.

[13] BRENNAN, L. B., ISAAC, D. H., ARNOLD, J. C., "Recycling of acrylonitrile-butadiene-styrene and high-impact polystyrene from waste computer equipment", Journal of Applied Polymer Science, v. 86, n. 3, pp.572-578, 2002.

[14] LUNA, C. B.B., SILVA, D. F., BASÍLIO, S. K. T., et al., "Desenvolvimento de blendas poliméricas visando a tenacificação dos polímeros: uma revisão", Semina: Ciências Exatas e Tecnológicas, v. 36, n. 1, pp. 67-80, 2015.

[15] ZHANG, J., CHEN, H., ZHOU, Y., et al., "Compatibility of waste rubber powder/polystyrene blends by the addition of styrene grafted styrene butadiene rubber copolymer: effect on morphology and properties", Polymer Bulletin, v. 70, n. 10, pp. 2829- 2841, 2013.

[16] QIN, J., ARGON, A. S., COHEN, R. E., "Toughening of glassy polystyrene through ternary blending that combines low molecular weight polybutadiene diluents and ABS or HIPS-Type composite particles", Journal of Applied Polymer Science, v. 14, n. 3, pp.2319-2328, 1999.

[17] SIQUEIRA, D. F., BRUNS, R. E., NUNES, S. P., "Compatibilização e otimização de blendas poliméricas", Polímeros: Ciência e Tecnologia , v. 3, n. 2, pp. 15-19, 1993. 
[18] FUHRMANN, I., KOCSIS-KARGER, J., KAISERLAUTERN. Einfluß von altgummipartikeln auf das mechanische eigenschaftsprofil von thermoplast-blends. KGK Kautschuk Gummi Kunststoffe, v. 52, n. 12, pp. 836-841, 1999.

[19] COSTA, H. M., RAMOS, V. D., SILVA, W. S., et al., "Otimização de Propriedades Mecânicas de Misturas Ternárias de Polipropileno (PP)/Borracha de Etileno-Propileno-Dieno (EPDM)/Pó de Pneus (SRT) sob Tração e Impacto usando a Metodologia da Superfície de Resposta (MSR)", Polímeros: Ciência e Tecnologia, v. 22, n. 1, p. 27-33, 2012.

[20] LUNA, C. B. B., SILVA, D. F., ARAÚJO, E. M., et al., "Estudo do comportamento mecânico, termomecânico e morfológico de misturas de poliestireno/composto de borracha reciclada (SBR)", Revista Matéria, v. 20, n. 2, pp. 322-334, 2015.

[21] LUNA, C. B. B., SILVA, D. F., ARAÚJO, E. M., "Estudo do comportamento de blendas de poliamida 6/resíduos de borracha da indústria de calçados”, Revista Univap, v. 20, n. 36, pp. 98-110, 2014.

[22] ZHAO, J., WEI, D., WANG, Z. "Thermoplastic elastomers based on high-impact polystyrene/waste styrene butadiene rubber powder blends enhanced by styrene-butadiene-styrene block copolymer and aromatic oil”, Journal of Macromolecular Science, Part B: Physics, v. 54, n. 3, pp. 262-274, 2015.

[23] PIORKOWSKA, E., ARGON, A. S., COHEN, R. E. "Size effect of compliant rubbery particles on craze plasticity in polystyrene", Macromolecules, v. 23, n. 16, pp. 3838-3848, 1990.

[24] CASTELlANI, L., MAESTRINI, C. "Rubber-like tensile behaviour of yielded high-impact polystyrene", Polymer, v. 31, n. 12, pp. 2278-2286, 1990,

[25] FLEMING, R. R., PARDINI, L. C., ALVES, N. P., et al., “Avaliação de blendas de PAN/polímeros biodegradáveis por calorimetria", Revista Matéria, v. 17, n. 1, pp. 909-918, 2012.

[26] GILBERT, D. G., DONALD, A. M., “Toughening mechanisms in high impact polystyrene", Journal of Materials Science, v. 21, n. 5, pp. 1819-1823, 1986.

[27] MATHUR, D., NAUMAN, E. B., "Impact strength of bulk PS/PB blends: compatibilization and fracture studies”, Journal of Applied Polymer Science, v. 72, n. 9, pp.1151-1164, 1999.

[28] SHIH, R. S., KUO, S. W., CHANG, F. C. "Thermal and mechanical properties of microcellular thermoplastic SBS/PS/SBR blend: effect of crosslinking”, Polymer, v. 52, n. 3, pp. 752-759, 2011.

[29] COUtinho, F. M. B., CostA, M. P. M., GuimarÃES, M. J. O. C., et al., "Preparation and characterization of high-impact polystyrene using different types of polybutadiene", Journal of Applied Polymer Science, v. 108, n. 1, pp.406-413, 2008.

[30] JAR, P. Y. B., TODO, M., TAKAHASHI, K., et al., "Finite element model of thermal stress effects on stress distributions in rubber modified glassy polymers: part 1 - single particle model", Plastics, Rubber and Composites, v. 30, n. 3, pp.101-109, 2001.

[31] GIOVANELLA, J., JANCZKOWSKI, R., SOARES, G. C., et al., "Reciclagem de materiais: estudo das propriedades mecânicas de policarbonato reciclado de discos compactos", Revista Matéria, v. 13, n. 4, pp. 643-649, 2008.

[32] TANG, C. Y., TSUI, C. P., SHEN, W., et al., "Modelling of non-linear stress-strain behaviour of HIPS with craze damage in tensile loading-unloading process", Polymer Testing, v. 20, n. 1, pp. 15-27, 2001.

[33] GRASSI, V. G., FORTE, M. M. C. “Aspectos morfológicos e relação estrutura-propriedades de poliestireno de alto Impacto”, Polímeros: Ciência e Tecnologia, v.11, n.3, pp.158-168, 2001.

[34] AGUNG, E. H., SAPUAN, S. M., HAMDAN, M. M., et al., "Study on abaca (Musa textilis Nee) fibre reinforced high impact polystyrene (HIPS) composites by thermogravimetric analysis (TGA)", International Journal of the Physical Sciences, v, 6, n. 8, pp. 2100-2106, 2011.

[35] SERRANO, C. L. R. Uso de resíduo de SBR proveniente da indústria de calçados em composições de SBR, Tese de D.Sc., PPGEM/UFRGS, Rio Grande do Sul, RS, Brasil, 2009.

[36] LIANG, H., HARDY, J. M., RODRIGUES, D., et al., "EPDM recycled rubber powder characterization: thermal and thermogravimetric analysis", Rubber Chemistry and Technology, v. 87, n. 3, pp. 538-556, 2014.

[37] GUO, Z., FANG, Z., TONG, L. "Application of percolation model on the brittle to ductile transition for polystyrene and polyolefin elastomer blends", Express Polymer Letters, v. 1, n. 1, pp. 37-43, 2007.

[38] JOSEPH, S., LAUPRÊTRE, F., NEGRELL, C., et al., "Compatibilising action of random and triblock copolymers of poly(styrene-butadiene) in polystyrene/polybutadiene blends: A study by electron microscopy, solid state NMR spectroscopy and mechanical measurements", Polymer, v. 46, n. 22, pp. 9385 9395, 2005. 
[39] MÉlo, T. J. A., CARVALHO, L. H., CALUMBY, R. B., et al., "Propriedades mecânicas e morfologia de uma blenda polimérica de PP/HIPS compatibilizada com SEBS", Polímeros: Ciência e Tecnologia, v. 10, n. 2, pp. 82-89, 2000.

[40] ALFARRAJ, A., NAUMAN, E. B. "Super HIPS: improved high impact polystyrene with two sources of rubber particles, Polymer, v. 45, n. 25, pp. 8435-8442, 2004.

[41] ZHU, L. D., YANG, H. Y., CAI, G. D., et al., "Submicrometer-sized rubber particles as "craze-bridge" for toughening polystyrene/high-impact polystyrene", Journal of Applied Polymer Science, v. 129, n. 1, pp.224-229, 2013.

\section{ERRATA}

No artigo: "Efeito dos agentes de compatibilização SBS e SEBS-MA no desempenho de misturas de poliestireno/resíduo de borracha de SBR". Com o número do DOI: 10.1590/S1517-707620160003.0061, publicado no periódico Revista Matéria, 21(3):129-140.

Na página 632, Onde se lia:

"Carlos Bruno Barreto Luna', Divânia Ferreira da Silva1, Edcleide Maria Araújo"

\section{Leia-se:}

"Carlos Bruno Barreto Luna ${ }^{1}$, Divânia Ferreira da Silva ${ }^{1}$, Edcleide Maria Araújo ${ }^{1}$, Tomás Jeferson Alves de Melo ${ }^{1}$; Amanda Dantas de Oliveira"

Na página 632, Onde se lia:

"Unidade Acadêmica de Enqenharia de Materiais, UAEMa/CCT/UFCG, Rua: Aprígio Veloso, 882, cep 58429-140, Campina Grande, PB".

\section{Leia-se:}

"'Unidade Acadêmica de Engenharia de Materiais, UAEMa/CCT/UFCG, Rua: Aprígio Veloso, 882, cep 58429-140, Campina Grande, PB".

"2 Departamento de Engenharia de Materiais, Centro de Desenvolvimento Tecnológico/UFPel, Rua: Félix da Cunha, 809, CEP 96010-000, Pelotas, RS". 
Na página 636, Onde se lia:

Uma série de seis amostras foi ensaiada e a temperatura de deflexão térmica medida.

\section{Leia-se:}

Uma série de três amostras foi ensaiada e a temperatura de deflexão térmica medida.

Na página 638, Onde se lia:

Por outro lado, a boa resistência à tração do PS

\section{Leia-se:}

Por outro lado, a boa resistência à flexão do PS

\footnotetext{
(c) $\mathrm{EY}$ Todo o conteúdo deste periódico, exceto onde está identificado, está licenciado sob
} uma Licença Creative Commons 